\title{
The Importance of Charge-Separation Reactions in Tandem Mass Spectrometry of Doubly Protonated Angiotensin II Formed by Electrospray Ionization: Experimental Considerations and Structural Implications
}

\author{
Jeanette Adams, Fred H. Strobel, Alex Reiter, and M. Cameron Sullards \\ Department of Chemistry and the Emory University Mass Spectrometry Center, Emory University, Atlanta, \\ Georgia, USA
}

\begin{abstract}
The occurrence of charge-separation reactions in tandem mass spectrometry of doubly protonated angiotensin II is demonstrated by the use of mass-analyzed ion kinetic energy spectrometry (MIKES) and kinetic energy release distributions (KERDs). Linked scans at a constant $B / E$ severely discriminate against product ions formed by charge-separation reactions. Although the products are significantly more abundant in MIKES experiments, instrumental discrimination still makes quantitation of relative product ion abundances highly inaccurate. The most probable KERs $\left(T_{\text {m.p. }}\right)$ and the average KERs $\left(T_{\text {ave }}\right)$ of the reactions are determined from the KERDs, and these values are compared to the KERs determined from the peak widths at half-height $\left(T_{0.5}\right)$. The measurement of $T_{0.5}$ is a poor approximation to $T_{\text {m.p. }}$ and $T_{\text {ave: }}$ The $T_{\text {m.p. }}$ is used to calculate a most probable intercharge distance, which is compared to results from molecular dynamics calculations. The results provide evidence with regard to the mechanisms of fragmentation of multiply charged ions and the location of the charge site in relation to the decomposition reactions. (J Am Soc Mass Spectrom 1996, 7, 30-41)
\end{abstract}

$\mathrm{E}$ lectrospray ionization mass spectrometry (ESIMS) is one of the most exciting recent develJopments in structure determination of biomolecules. ESI-MS has provided a method to produce multiply charged gas-phase ions of large molecules-ions that provide critical information with regard to molecular mass at least up to $5 \mathrm{Mu}$ [1]. Coupling ESI-MS with bimolecular reactions has provided important new insights on the relationship between gas-phase and solution conformations of proteins [2]. ESI and tandem mass spectrometry have opened new avenues to determine primary sequence information for higher mass peptides $(7-60 \mathrm{ku})$ by using collision-induced decompositions (CID) and either quadrupole [3a, b], Fourier transform (FT) [3c], or multisector [3d] mass spectrometers. The structural information in the CID spectra is gleaned from fragmentation reactions that frequently involve formation of product ions that have lower charge states than their precursors.

One fundamental question with regard to tandem mass spectrometry of multiply charged peptides is the

Address reprint requests to Professor Jeanette Adams, Department of Chemistry, Emory University, Atlanta, GA 30322. mechanistic origin of product ions of low charge states [4]. For example, a doubly protonated $[\mathrm{M}+2 \mathrm{H}]^{2+}$ peptide ion could decompose via a charge-separation reaction to give two singly charged complementary product ions, such as $\mathrm{b}_{n}^{+}$and $\mathrm{y}_{m-n}^{\prime \prime}$ ions, in which $m$ is the total number of amino acid residues in the peptide and $n$ is the number of residues in the $\mathrm{b}^{+}$ions. (This nomenclature follows that of Roepstorff and Fohlman [5] except the letters are lowercase, which follows the nomenclature of Biemann and co-workers [6b, c]. The alphabetical notation represents direct cleavage of the backbone of a neutral nonzwitterionic peptide and the primes represent the number of extra hydrogens that are contained in the product ions as a result of either protonation or transfer of a hydrogen to the product ions in the decomposition reactions. This nomenclature is unambiguous because it gives the exact masses of the product ions [4c, d].) Frequently, only the high mass ion of the complementary pair is abundant in tandem mass spectra acquired by using quadrupole and sector instruments [4]. The low mass complementary ion is either missing or of low abundance. McLafferty and co-workers [3c] have shown that some complementary ions can be detected in electrospray ionization-Fourier transform mass spectrometry (ESI-FTMS) spectra of highly charged car- 
bonic anhydrase. The total abundance of $\mathrm{y}_{m-n}^{x+}$ ions is, however, significantly more abundant than the total abundance of $b_{n}^{z-x+}$ inns ( $z$ is the total charge of the precursor ion). Furthermore, some highly abundant $\mathrm{y}_{m-n}^{x+}$ ions have no complementary $\mathrm{b}_{n}^{z-x+}$ ions [3c]. Consequently, there has been no unequivocal evidence yet presented that reveals whether or not these types of charge-separation reactions account for either the detected or the missing complementary ions.

Another fundamental question that is still open for debate is the role of charge location and Coulomb repulsion in the tandem mass spectrometry fragmentation pathways [7]. For stable precursor ions, there is compelling evidence that the most likely locations of protons in multiply protonated peptides are basic amino acid residues (Arg, Lys, His) [8]. Similar evidence exists for the locations of anionic sites in stable multiply deprotonated peptides [9]. The location of protons in positive ions would be related closely to the gas-phase basicity, and in some cases the solution basicity, of the charged functional group, at least if Coulomb repulsion were minimal. For precursors ions that decompose, however, the situation may be more complex $[7 b-d]$. There is currently no concrete evidence with regard to the location of charge in relation to tandem mass spectrometry decomposition pathways of multiply charged ions.

A closely related question involves the role of the charge site in the mechanisms for the decomposition reactions. The generally accepted mechanism for formation of $b_{n}^{+}$ions from singly charged $[\mathrm{M}+\mathrm{H}]^{+}$ions involves protonation of an amide nitrogen followed by a charge-induced direct cleavage of the amide bond to give an acylium $b_{n}^{+}$ion and a neutral $y_{m-n}^{\prime}$ species [6]. Currently, this same mechanism is believed to hold for multiply protonated peptides [4c, d], except perhaps for peptides that contain Ser [7c]. There are at least two mechanisms that have been substantiated by deuterium labeling for formation of $\mathrm{y}_{m-n}^{\prime+}$ ions from singly protonated peptides [10]. These mechanisms involve hydrogen rearrangements, and one is believed to hold for multiply protonated peptides [4c, d].

Here we present metastable ion tandem mass spectrometry data and theoretical structural calculations that address the foregoing questions. Metastable ion mass-analyzed ion kinetic energy spectrometry (MIKES) conclusively reveal the occurrence of chargeseparation reactions for doubly charged precursor ions formed by ESI. A comparison of data acquired using scans at a constant $B / E$ versus MIKES experiments shows why low-mass complementary ions are missing in scans at a constant $B / E$. Furthermore, the kinetic energy release distributions (KERDs) and the resulting most probable kinetic energy releases (KERs) are used in conjunction with structural calculations to directly address the location of charge in the decomposing precursor ions. This information provides evidence with regard to the role of the charge site in the mechanisms of decomposition.

\section{Experimental}

\section{General Methods}

Metastable ion decompositions of $[\mathrm{M}+2 \mathrm{H}]^{2+}$ ions of angiotensin II (AspArgValTyrlleHisProPhe) were studied by using a JEOL (Peabody, MA) JMSSX102/SX102A/E (B $E_{1}-B_{2} E_{2}-E_{3}$ or MS1-MS2-MS3) five-sector, tandem mass spectrometer (Figure 1). Ion source 1 (Figure 1) was a JEOL Generation 2 ESI source operated at $5 \mathrm{kV}$. The precursor ions were electrosprayed from a solution of 49:49:2 $\mathrm{CH}_{3} \mathrm{OH}$ / $\mathrm{H}_{2} \mathrm{O} / \mathrm{H}_{3} \mathrm{CCO}_{2} \mathrm{H}$ in which the peptide was at a concentration of $25 \mathrm{pmol} \mu \mathrm{L}^{-1}$. The ion source capillary and skimmers were tuned to optimize transmission and minimize the kinetic energy distribution of the precursor ions.

\section{Tandem Mass Spectrometry B /E Experiments}

One set of experiments involved the use of MS1 $\left(B_{1} E_{1}\right)$ to mass- and energy-select the precursor ions at a double-focusing resolving power $\left(R_{\mathrm{DF}}\right)$.of $1000(10 \%$ valley). MS2-MS3 $\left(B_{2} E_{2}-E_{3}\right)$ was used in doublefocused scans at a constant $B / E\left(R_{\mathrm{DF}}=1000\right.$ at $10 \%$ valley) to observe decompositions in the third field-free region between MS1 and MS2 (Figure 1). In these experiments, the final collector slit $\left(\mathrm{S}_{\mathrm{C} 3}\right)$ was fully open so that MS3 $\left(E_{3}\right)$ simply operated as an ion guide [11]. MS2-MS3 was scanned to $10 \mathrm{kV}$ to observe product

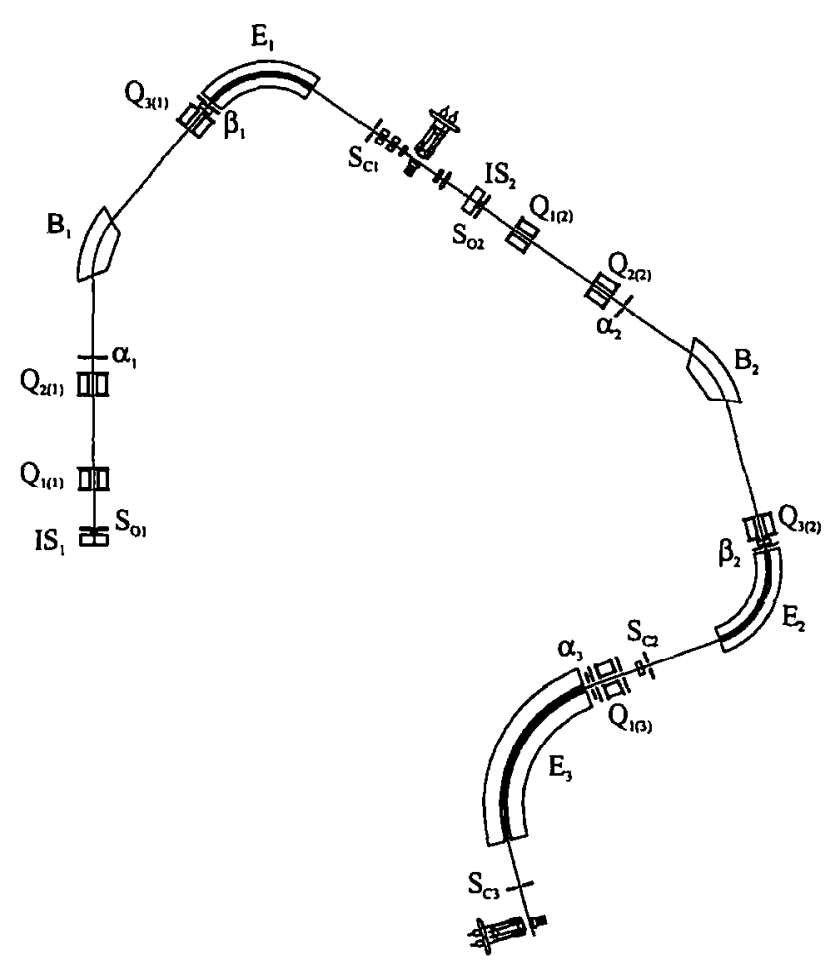

Figure 1. Ion optics of the JEOL JMS-SX102/SX102A/E tandem mass spectrometer. 
ions of higher mass-to-charge ratios (lower charge states) than the precursor ions [12].

\section{Tandem Mass Spectrometry Full-Scan Mass- Analyzed Ion Kinetic Energy Spectrometry}

Another set of experiments involved the use of both MS1 and MS2 to mass- and energy-select, the precursor ions at double-focusing resolving powers of 1000 (10\% valley). MS3 was scanned to obtain MIKES spectra of decompositions in the fifth field-free region between MS2 and MS3 (Figure 1). In these experiments, $\mathrm{S}_{\mathrm{C} 3}$ was fully open to maximize ion transmission. MS3 was scanned to $10 \mathrm{kV}$ to observe product ions of higher mass-to-charge ratios than the precursors [12].

\section{Kinetic Energy Release Distributions}

Kinetic energy release distributions (KERDs) were obtained from narrow-scan MIKES experiments by using analog filtering of $100 \mathrm{~Hz}$. Here $\mathrm{S}_{\mathrm{C} 3}$ was narrowed to reduce the transmission of the main beam by $10-20 \%$ $\left(\mathrm{S}_{\mathrm{C} 2}=147 \mu \mathrm{m}\right.$ and $\left.\mathrm{S}_{\mathrm{C} 3}=200 \mu \mathrm{m}\right)$. This produced $\mathrm{a}$ Gaussian-shaped precursor ion peak in the energy spectra and a realizable (measured) energy-resolving power of 1000 (precursor ion energy width of approximately $6 \mathrm{eV}$ at half-height). In this way, the kinetic energy distribution of the main beam limited the energy-resolving power of $E_{3}$, not the slit settings [11].

Individual MIKES spectra of the precursor ion and each product ion were acquired by signal-averaging 2-s MIKES scans over a narrow energy range for periods of 10-180 $\mathrm{min}$. The kinetic energy distribution of the precursor ion was then deconvoluted from the product ion peak [13]. The resulting product ion peak was smoothed by multiple iterations of a 21-point Savitzky-Golay smooth [14] and the KERD was calculated from the smoothed data in a manner that accounts for $y$ - and $z$-axial instrumental discrimination [15]. The most probable KER $\left(T_{\text {m.p. }}\right)$ was calculated from the maximum of the KERD. The average KER ( $T_{\text {ave. }}$ ) was calculated from the KERD by integration. The KER at half-height $\left(T_{0.5}\right)$ was obtained from the energy width of the deconvoluted and smoothed product ion peak at $50 \%$ peak height using eq 1 [16], in which $y$ is the product ion charge $(z), m_{0}$ is the mass of the precursor ion $(u), \Delta E$ is the energy width of the product ion at $50 \%$ peak height (electronvolts), $x$ is the precursor ion charge $(z), m_{2}$ and $m_{3}$ are the masses of product ions $(u)$, and $E_{0}$ is the accelerating voltage (volts). In calculating the $T_{0.5}$ values, there was no need to correct the energy width of the product ion [eq 2 [17], in which $\Delta E_{\text {corr. }}$ is the corrected energy width of product and $w_{\text {prec. }}$ is the measured energy width of precursor at $50 \%$ peak height (electronvolts)] because of the deconvolution of the precursor kinetic energy distribution. Furthermore, this width correction assumes a Gaussian-shaped product ion peak [17], which is not the case for the ions studied here.

$$
\begin{gathered}
T_{0.5}=\left[y m_{0}(\Delta E)\right]^{2} /\left[16 x m_{2} m_{3} E_{0}\right] \\
\Delta E_{\text {corr. }}=\left\{(\Delta E)^{2}-\left[\left(m_{2} / m_{0}\right)\left(x E_{0}\right)\left(w_{\text {prec. }}\right)\right]^{2}\right\}^{1 / 2}
\end{gathered}
$$

\section{Semiempirical and SYBYL Dynamics Calculations}

Semiempirical AM1 calculations [18] were used in conjunction with SYBYL (version 6.0) molecular dynamics calculations (Tripos Associates, Inc., St. Louis, MO) to obtain the starting structures for the dynamics calculations. The first step was to build a dipeptide that contained a C-terminal Phe and an $\mathrm{N}$-terminal amino acid; the latter was either Asp, Arg, His, or Pro. One proton was placed on the C-terminal amino acid and the other was placed on the $\mathrm{N}$-terminal amino acid. The charge of the dipeptide was then calculated by using AM1. The remainder of the molecule was built by using SYBYL and the charge of the neutral molecule was calculated by using the method of Pullman and co-workers [19]. The doubly protonated dipeptide was then broken into two separate fragments and joined to the remainder of the molecule to produce the final doubly charged angiotensin II ion. This species was energy-minimized $(0 \mathrm{~K})$ by using SYBYL to obtain a starting structure to use in the dynamics calculations. All SYBYL calculations were performed by using the newer Kollman force field, which is optimized for peptides and proteins and is an improved version of AMBER [20].

The dynamics calculations involved heating the doubly charged ions to different temperatures (500 and $1000 \mathrm{~K}$ ) for either 40 or $1000 \mathrm{ps}$ in 0.001 -ps steps. The structures were instantaneously sampled either every 0.8 or $0.5 \mathrm{ps}$, respectively. The distance between the charges was calculated as the average ( \pm standard deviation) of either 50 or 2000 structures, respectively. Some calculations also were performed in which the sampled structures were energy-minimized $(0 \mathrm{~K})$.

\section{Results}

\section{Mass Spectral Data}

The tandem mass spectrometry $B / E$ spectrum of metastable ion decompositions in the third field-free region between MS1 and MS2 shows product ions that are double focused (Figure $2 \mathrm{~A}$ ). The $[\mathrm{M}+2 \mathrm{H}]^{2+}$ precursors $(m / z 523.9)$ decompose to give two abundant doubly charged product ions: $y_{7}^{\prime \prime \prime 2}+(m / z 466.4)$ and $\left[b_{7}^{\prime \prime}+\mathrm{OH}\right]^{2+}(m / z 450.3)$. The $y_{7}^{\prime \prime 2+}$ ions are formed by cleavage of the amide bond between Asp and Arg (Structure 1) with transfer of a hydrogen from the neutral leaving group to the fragment ion, which also contains two protons from the ionization process. The $\left[b_{7}^{\prime \prime}+\mathrm{OH}\right]^{2+}$ ions arise by cleavage of the amide bond between Pro and Phe (Structure 1) with concomitant 

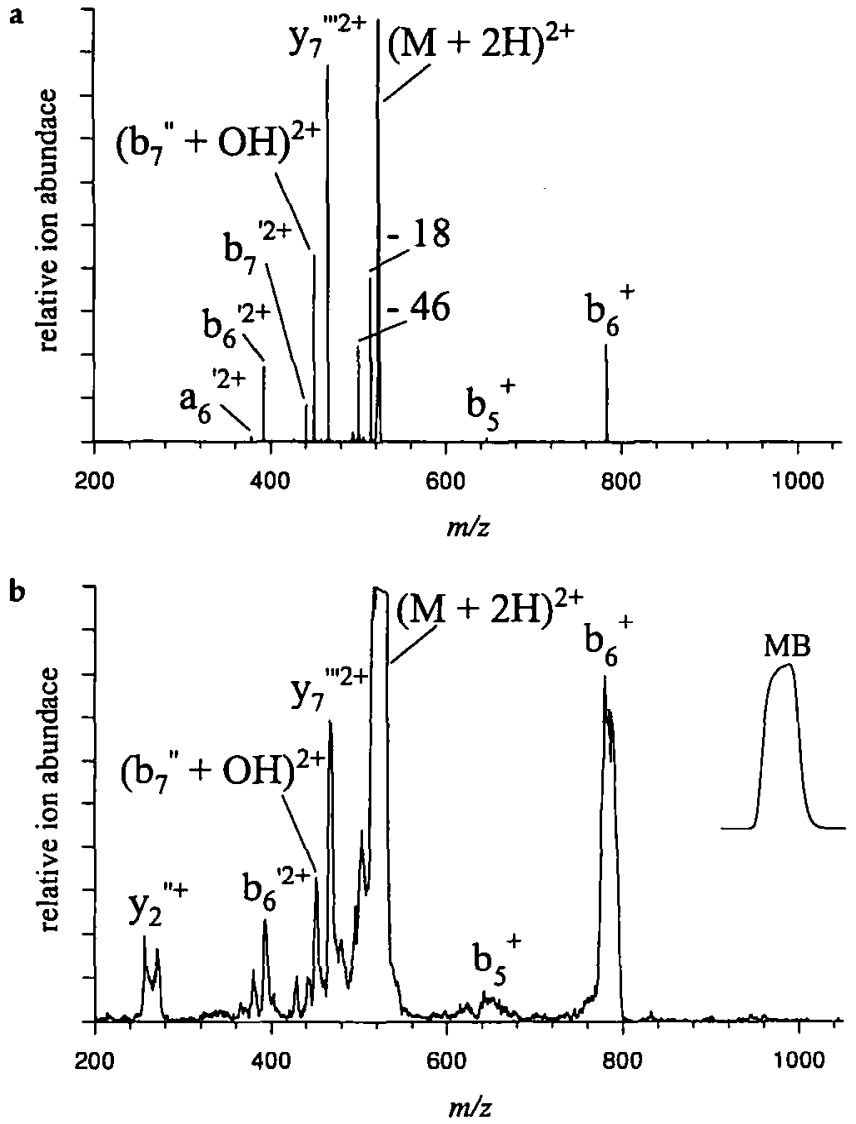

Figure 2. Tandem mass spectra of $[\mathrm{M}+2 \mathrm{H}]^{2+}$ ions of angiotensin II: (A) B/E spectrum; (B) MIKES spectrum. The small inset in (B) shows the precursor ion peak shape.

transfer of the $\mathrm{C}$-terminal carboxylic acid $\mathrm{OH}$ group to the Pro carbonyl carbon [21]. The $\left[b_{7}^{\prime \prime}+\mathrm{OH}\right]^{2+}$ ions also contain two protons from the ionization process. In addition to other weakly abundant doubly charged product ions, there are also two singly charged products: $\mathrm{b}_{6}^{+}(m / z 784.4)$ and $\mathrm{b}_{5}^{+}(m / z$ 647.4) ions. If these two ions were formed by charge-separation reactions, one would expect to observe complementary $\mathrm{y}_{2}^{\prime \prime}(\mathrm{m} / \mathrm{z}$ 263.4) and $y_{3}^{\prime \prime+}(m / z 400.4)$ ions. Neither of these two products, however, is clearly discernible.

The full-scan MIKES spectrum of metastable ion decompositions in the fifth field-free region between MS2 and MS3 gives significantly different relative ion abundances for the singly charged ions (Figure 2B). In

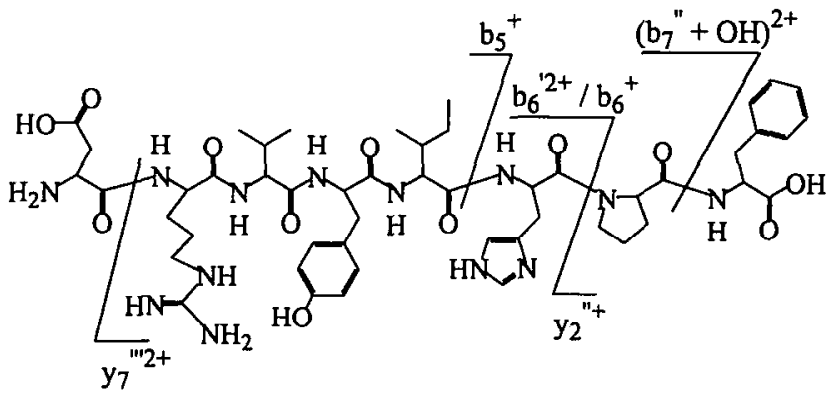

Structure 1 particular, the $\mathrm{b}_{6}^{+}$ions are highly abundant and $\mathrm{y}_{2}^{\prime \prime+}$ ions $\left(m / z\right.$ 263.2) are detected easily. The $b_{5}^{+}$ions appear as a broad peak: Their complementary $\mathrm{y}_{3}^{\prime \prime+}$ ions may be present but buried under the ion signal for the $\mathbf{b}_{6}^{\prime 2+}$ ions. Even though the energy-resolving power of MS3 is low (see inset in Figure 2B), the peak for the $\mathrm{y}_{2}^{\prime \prime}$ ions is dish-shaped and broad. The low-mass $\mathrm{y}_{2}^{\prime \prime}$ ions are of significantly lower abundances than the high-mass $b_{6}^{+}$ions.

The shapes of the $b_{6}^{+}$and $y_{2}^{\prime \prime+}$ product-ion peaks are shown more clearly in spectra acquired by using narrow energy scans (Figure 3). Here, the realizable energy-resolving power of E3 is 1000 and the precursor ion beam (insets in Figure 3) is narrow in .energy compared to the product ion peaks. Thus, the features of the singly charged $b_{6}^{+}$(Figure $3 \mathrm{~A}$ ) and $\mathrm{y}_{2}^{\prime \prime+}$ (Figure 3B) ion peaks are well resolved and clearly shown to be broad and dished. Of relevance is the fact that the peak for the low-mass $y_{2}^{\prime \prime}$ ion (Figure $3 B$ ) is significantly more dished than its high-mass counterpart.

The smooth, solid lines through the data in Figure 3 show the results of deconvolution and smoothing. From these data, the KERDs are calculated (Figure 4). The KERDs for both product ions are virtually identical and give a most probable KER $\left(T_{\text {m.p. }}\right)$ of $0.902 \pm 0.000$
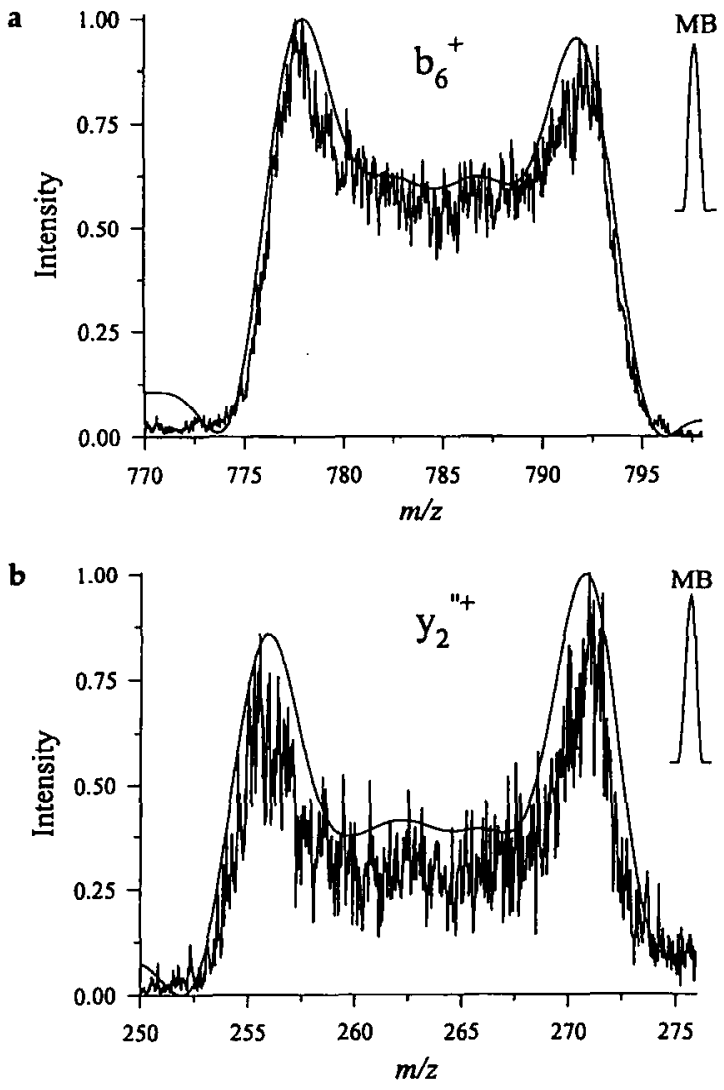

Figure 3. Narrow-scan MIKES spectra of (A) $b_{6}^{+}$and (B) $y_{2}^{\prime \prime}$ product ions. Results from deconvolution of the precursor ion kinetic energy distribution and smoothing are the smooth solid lines that are superimposed over the raw data. The small insets show the precursor ion peak shapes scaled in energy to the energy widths of the product-ion peaks. 


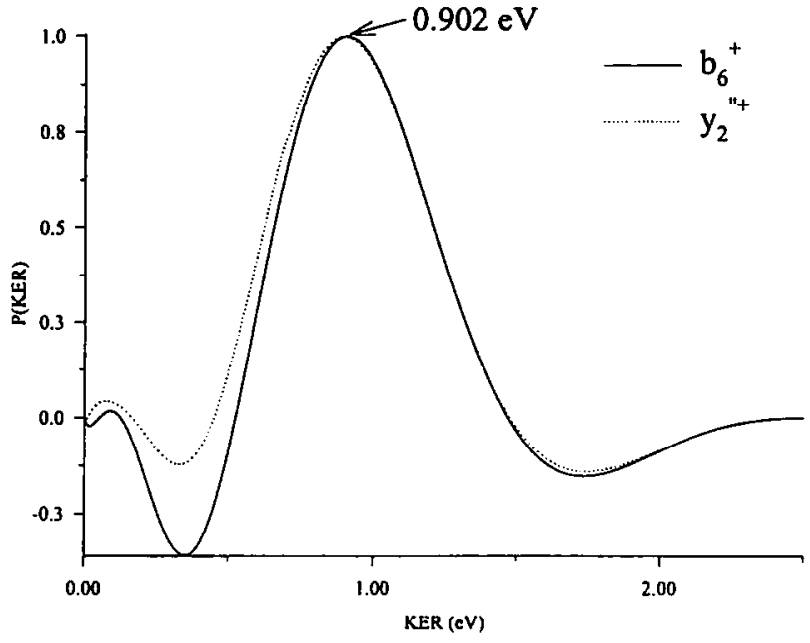

Figure 4. KERDs for the $b_{6}^{+}$(solid line) and $y_{2}^{\prime \prime}$ (dotted line) product ions calculated from the deconvoluted and smoothed curves shown in Figure 3.

$\mathrm{eV}$. These data show that these two product ions are indeed complementary and are formed via the same transition state in a charge-separation reaction.

\section{Structural Calculations}

Dynamics calculations were performed to address possible locations of the charges in the precursor $[\mathrm{M}+$ $2 \mathrm{H}]^{2+}$ ions to derive an intercharge distance. Several issues were addressed: (1) the effect of different dynamical heating times; (2) the effect of different dynamical heating temperatures; (3) the effect of energy minimization on the results.

Two sets of dynamics calculations were performed at $1000 \mathrm{~K}$ to address the effect of different heating times. Both starting structures contained one proton on the Arg side chain and the other on the C-terminal carboxylic acid carbonyl oxygen. The results, plotted as time (picoseconds) versus intercharge distance (angstroms) for a total time of either $1 \mathrm{~ns}$ (Figure 5A) or $40 \mathrm{ps}$ (Figure $5 \mathrm{~B}$, dotted line), give virtually the same intercharge distances $(15.5 \pm 4.1$ versus $15.8 \pm 3.1$ $\AA$, respectively). Furthermore, structures acquired during the first 40 ps of the 1-ns heating period (solid line in Figure 5B) give virtually the same intercharge distance $(15.4 \pm 3.7 \AA)$ as from the entire 1-ns heating period. Although a longer dynamical heating period is expected to give more reliable results overall, the computational expense is significantly greater. Consequently, all subsequent calculations were performed by using a 40-ps heating period.

Intercharge distances for the calculations at either 1000 or $500 \mathrm{~K}$ or after energy minimization to $0 \mathrm{~K}$ are given in Table 1. All the distances for each set of structures are within standard deviations. Even so, the intercharge distances for the $1000-\mathrm{K}$ structures are preferred because they more realistically reflect the experimental conditions: The decomposing precursor ions
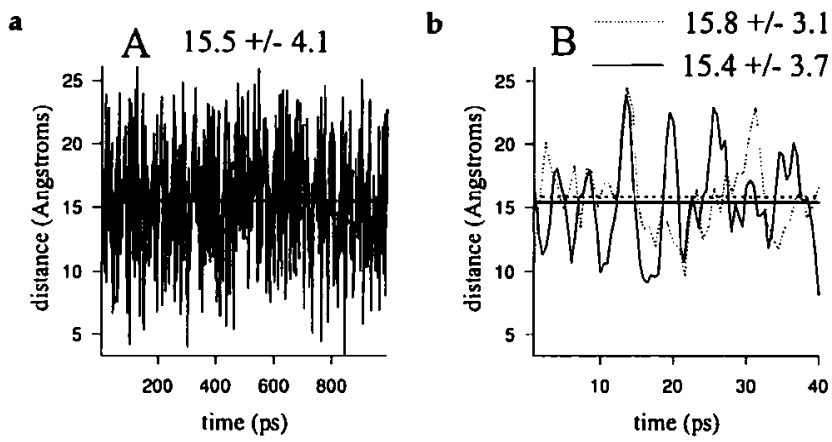

Figure 5. Plots of time versus intercharge distance for dynamics calculations performed at a dynamical temperature of $1000 \mathrm{~K}$ for a total heating time of $1 \mathrm{~ns}(\mathrm{~A})$ and $40 \mathrm{ps}(\mathrm{B})$. The average values are shown as horizontal lines through the plots and denoted above the plots. The solid-line data in (B) are results for the first 40 ps of the data shown in (A); the dotted-line data in (B) are results for a separate set of calculations performed over a heating period of 40 ps.

are obviously not in their $0-\mathrm{K}$ ground states. The most probable rate constants for the metastable ion reactions are $1.83 \times 10^{4} \mathrm{~s}^{-1}$ for the third field-free region and $1.01 \times 10^{4} \mathrm{~s}^{-1}$ for the fifth field-free region [22]. (The rate constants give most probable precursor ion lifetimes of $55 \mu \mathrm{s}$ for the third field-free region and $99 \mu \mathrm{s}$ for the fifth field-free region.) Using the most probable rate constants, an estimated log frequency factor $(A)$ of 12 [23], an $E_{0}$ of from 0.8 to $1.8 \mathrm{eV}$ [23], and the simple Arrhenius rate equation gives a temperature range of $500-1000 \mathrm{~K}$ for the ions if they were undergoing thermally induced reactions. Thus, our assumption is that the intercharge distance is best approximated by the $1000-\mathrm{K}$ structures because this temperature best represents the vibrational energies of the ions that decompose in the fifth field-free region.

Although the "temperature" of the ions is approximated by using analogies to thermal reactions, the use of "hot" structures obtained from dynamics calculations to mimic experimental conditions is not unprecedented. Bowers and co-workers [24], who used a dynamics approach similar to that presented here, reported a strong correlation between average structures predicted by $300-\mathrm{K}$ SYBYL molecular dynamics calculations and $300-\mathrm{K}$ experimental results from ion

Table 1. Summary of intercharge distances $( \pm$ standard deviation in angstroms) obtained from SYBYL dynamics calculations by using energy-minimized starting structures that contain one proton located on the C-terminal carboxylic acid carbonyl oxygen ${ }^{a}$

\begin{tabular}{lllc}
\hline $\begin{array}{c}\text { Location of } \\
\text { second proton }\end{array}$ & $\begin{array}{l}\cdot 500-\mathrm{K} \\
\text { structures }\end{array}$ & $\begin{array}{c}1000-\mathrm{K} \\
\text { structures }\end{array}$ & $\begin{array}{c}\text { Energy-minimized } \\
1000-\mathrm{K}_{\text {structures }}{ }^{\mathrm{b}}\end{array}$ \\
\hline \hline N-terminal $\mathrm{NH}_{2}$ & $10.9(2.3)$ & $12.5(4.0)$ & $11.6(3.5)$ \\
Asp carbonyl O & $12.7(3.2)$ & $13.4(3.4)$ & $12.8(2.9)$ \\
Arg imine N & $15.8(3.2)$ & $15.8(3.1)$ & $16.2(4.0)$ \\
His imidazole N & $8.99(1.1)$ & $8.89(2.1)$ & $9.22(1.4)$ \\
Pro amide N & $5.59(0.32)$ & $5.78(0.45)$ & $5.78(0.44)$ \\
\hline
\end{tabular}

Dynamics performed for a heating time of $40 \mathrm{ps}$.

Energy-minimized to $\mathrm{OK}$. 
mobility experiments. Their data thus also support the concept that energy-minimized structures may not accurately reflect structures of either $300-\mathrm{K}$ thermalized ions or ions that are otherwise vibrationally excited.

Related to the data in Table 1 are results from dynamics calculations for starting structures that contain one proton located on the carbonyl oxygen of the C-terminal amide (Table 2). Except for the structures that contain the second proton on the Asp side chain, the results in Table 2 give lower average distances between the two charges.

\section{Discussion}

The data presented in the preceding text impact several areas related to the use of tandem mass spectrometry to study charge-separation reactions of multiply charged ions formed by ESI: (1) instrumental discrimination in $B / E$ and MIKES experiments; (2) the actual occurrence of charge-separation reactions; (3) the acquisition of KER data; (4) the use of KERDs and structural calculations to obtain information with regard to intercharge distance, which is related to ion structure and reaction mechanisms.

\section{Instrumental Discrimination Against Products of Charge-Separation Reactions}

It is well known that sector mass spectrometers discriminate against ions that have high velocity distributions in the $y$ - (horizontal, perpendicular to flight path) and $z$ - (parallel to magnetic field) axial directions [15, 25]. Discrimination in the $y$ - and $z$-axial directions is caused by the finite widths and heights of the flight tube, slits, and the Herzog shields that precede and follow electrostatic analyzers (ESAs).

In the absence of KER, the $\mathrm{b}_{6}^{+}$and $\mathrm{y}_{2}^{\prime \prime}$ product ions would have zero velocities in the center-of-mass frame. In the laboratory frame, the two products would simply have the same velocity distribution as the precursor ions. The large release of kinetic energy in the charge-separation reaction, however, gives the product ions a significant velocity distribution in all directions. The KERDs are the same for both products, which means that the velocity distribution for the low-mass $\mathrm{y}_{2}^{\prime \prime+}$ ions is greater than that for the high-mass $\mathrm{b}_{6}^{+}$ions.

Table 2. Summary of intercharge distances ( \pm standard deviation in angstroms) obtained from SYBYL dynamics calculations by using energy-minimized starting structures that contain one proton located on the C-terminal amide carbonyl oxygen ${ }^{3}$

\begin{tabular}{lc}
\hline $\begin{array}{l}\text { Location of } \\
\text { second proton }\end{array}$ & $\begin{array}{c}1000-\mathrm{K} \\
\text { structures }\end{array}$ \\
\hline \hline N-terminal $\mathrm{NH}_{2}$ & $10.4(3.1)$ \\
Asp carbonyl O & $15.0(3.1)$ \\
Arg imine $\mathrm{N}$ & $15.4(3.4)$ \\
His imidazole N & $6.72(1.1)$ \\
\hline
\end{tabular}

${ }^{a}$ Dynamics performed for a heating time of 40 ps.
Therefore, the velocity distribution in the $y$ - and $z$-axial directions is proportionately greater for the low mass $\mathrm{y}_{2}^{\prime \prime}$ ions, which results in greater instrumental discrimination against them. This is shown in the MIKES spectra (Figure 2B and Figure 3) by the significantly reduced abundance and more severe dishing of the peak for the $\mathrm{y}_{2}^{\prime \prime}$ ions.

Discrimination against product ions in the $y$ - and $z$-axial directions is more significant in $B / E$ (Figure 2A) than MIKES (Figure 2B) experiments for two reasons. One is that the flight path of the product ions is significantly increased from an average of $1.1 \mathrm{~m}$ for the MIKES experiments to an average of $2.9 \mathrm{~m}$ for the $B / E$ experiments. The other reason is that there are a greater number of beam restrictors in the flight path for the $B / E$ experiments. These restrictors include all the slits (Figure 1), Herzog shields, and beam height restrictors in MS2 and MS3. It should be noted, however, that the dc-only quadrupoles in the $\mathrm{SX102}\left(\mathrm{Q}_{3}\right.$ for both MS1 and MS2 and $Q_{1}$ for MS3, in Figure 1) focus ions stigmatically so that $z$-axial discrimination is less than in other sector instruments [26].

Discrimination against velocity distributions in the $x$-axial (forward and reverse) direction in scans at a constant $B / E$ (Figure $2 \mathrm{~A}$ ) is caused by the relatively narrow double-focusing velocity bandpasses of the matched magnet $\left(B_{2}\right)$ and ESA $\left(E_{2}\right)$ [27]. The result is that ions that have significant $x$-axial velocity spreads may enter $B_{2}$, but may neither exit $B_{2}$ nor enter the Herzog shield that immediately precedes $E_{2}$ after velocity dispersion and angular focusing by $\mathrm{B}_{2}$. Consequently, the only product ions that can be double focused in scans at a constant $B / E$ have a relatively narrow $x$-axial velocity distribution. The distribution is centered around the laboratory-frame velocity (and kinetic energy) of the product ion in the absence of KER.

The effect of double-focusing $x$-axial discrimination can be quantified from the data shown here. We previously showed [11] that the SX102 can double focus a laboratory-frame $x$-axial kinetic energy spread of 130 $\mathrm{eV}$ for an ion of $m / z 103$ at $10 \mathrm{keV}$ in cases in which the $\beta$ slit is fully open. This gives a maximum kinetic energy spread of $\pm 65 \mathrm{eV}(\Delta E / E=1.3 \%)$ at $10 \mathrm{keV}$ that can be double focused. The $\mathrm{b}_{6}^{+}$and $\mathrm{y}_{2}^{\prime \prime}$ ions, however, have $x$-axial kinetic energy spreads of approximately $164 \mathrm{eV}$ (energy widths at 50\% peak height). This gives laboratory-frame kinetic energies of $7488 \pm 82 \mathrm{eV}(\Delta E / E=2.2 \%)$ for the $\mathrm{b}_{6}^{+}$ions and $2512 \pm 82 \mathrm{eV}(\Delta E / E=6.5 \%)$ for the $\mathrm{y}_{2}^{\prime \prime+}$ ions. This means that double-focusing $B_{2} E_{2}$ is only capable of double focusing and transmitting $59 \%(7488 \pm 49 \mathrm{eV})$ of the $b_{6}^{+}$ions and $20 \%(2512 \pm 16 \mathrm{eV})$ of the $\mathrm{y}_{2}^{\prime \prime}$ ions that enter $B_{2}$.

Low double-focusing transmission convoluted with $y$ - and $z$-axial discrimination that causes reduced transmission and dishing explains why the low mass singly charged ions are absent in the $B / E$ spectra. Most of the $20 \%$ of the $y_{2}^{\prime \prime}$ ions that have $x$-axial 
kinetic energies of $2512 \pm 16 \mathrm{eV}$ that could be double focused do not strike the detector because of $y$ - and $z$-axial discrimination. The low number of ions that are contained in the $2512 \pm 16-\mathrm{eV}$ spread that survive to the detector can be envisioned as the central part of the peak shown in Figure 3B. This low number of ions is indistinguishable from noise in the $B / E$ scan spectrum in Figure 2A.

The foregoing data impact several aspects of using tandem mass spectrometry to study decompositions of multiply charged ions formed by ESI. One is that relative ion abundances of products from chargeseparation reactions in scans at a constant $B / E$ are highly suspect [12]. Relative product ion abundances from MIKES scans are also suspect [12]. Furthermore, $x-, y-$, and $z$-axial discrimination is inversely related to mass. Consequently, the effect of the preceding discrimination must be taken into account when relative ion abundances are calculated. Thus, the kinetic method, if used directly to study charge-separation reactions of multiply charged proton-bound dimers [28] may give unreliable results.

\section{Occurrence of Charge-Separation Reactions}

The MIKES data and the virtually identical KERDs shown in Figure 4 unequivocally show that chargeseparation reactions occur from multiply charged precursor ions formed by ESI (also see ref 12). Previous [4] experiments that addressed this issue were inconclusive. Smith and co-workers $[4 a, b]$ concluded that charge-separation reactions such as shown here for the $\mathrm{b}_{6}^{+} / \mathrm{y}_{2}^{\prime+}$ pair were unlikely because the low-mass complementary ions were absent in tandem mass spectra acquired by using a triple quadrupole mass spectrometer. This experimental observation led them to hypothesize that collision-induced proton transfer and/or dissociative electron capture accounted for the missing low-mass ions. Results presented here show that proton transfer and/or dissociative electron capture are not involved in the chemistry because experiments here were conducted in the absence of collision gas. Missing low-mass ions in triple quadrupole experiments simply may be a result of instrumental discrimination: The rf-only quadrupole potential fields would have to be tuned to contain low-mass ions of high transverse velocities to observe the ions in the mass spectra.

Boyd and co-workers [4c, d] also addressed the issue of missing low-mass ions. They likewise found no evidence in support of either proton transfer or dissociative electron capture. Their data, however, supported a hypothesis that the weakly abundant or missing low-mass complementary ions are inherently unstable and decompose prior to detection. Indeed, their data [4c] show that $b_{n}^{+}$ions, which are missing or of low abundance in spectra of some doubly charged precursors, are less stable than their $y_{m-n}^{\prime \prime+}$ comple- ments, at least under CID conditions. Instability of the product ions is not relevant here, however, because weakly abundant $b_{6}^{+}$and highly abundant $y_{2}^{\prime \prime}$ ions for the $[\mathrm{M}+2 \mathrm{H}]^{2+}$ ions of angiotensin II would have been predicted with basis in their data: the opposite is observed. Tang and Boyd [4c] also performed metastable ion and CID MIKES experiments to try to document the occurrence of charge-separation reactions. Unfortunately, their MIKES data were inconclusive because only the high-mass ion of the complementary pair was observed. As mentioned before, the ability to observe the low-mass complementary ions in MIKES experiments performed here is the result of the stigmatic focusing ion optics of the JEOL, which reduces $z$-axial discrimination [26].

\section{Kinetic Energy Releases: Precursor Ion Kinetic Energy Distribution, $T_{m . p,}, T_{a v e,}$ and $T_{0.5}$}

There are several considerations for acquisition of KERDs for reactions that involve large releases of translational energy. Experimentally, the most important criterion is that the energy-resolving power of the ESA is high [29]. This also means that the precursor ions must have a narrow kinetic energy distribution. Computationally, the most important criterion is that the mathematical algorithm accounts for instrumental $y$ - and $z$-axial discrimination $[15,25]$.

The realizable, or measurable, energy-resolving power of any ESA is limited by three factors. Two of these-the energy dispersion of the ESA and the widths of the two energy-resolving slits that immediately precede and follow the ESA-are purely theoretical instrumental features defined by eq $3[11,26]$, in which $R_{\mathrm{E}}$ is the energy-resolving power, $A \gamma$ is the dispersion (micrometers), $A_{\mathrm{x}}$ is the magnification, $S_{0}$ is the width of the object slit of the ESA (micrometers), $S_{1}$ is the width of the image slit of the ESA (micrometers), and $\Delta$ is the image aberration (micrometers). The effect of poor theoretical energy-resolving power is demonstrated in the inset in Figure $2 \mathrm{~B}$, which shows the effect of having the image slit of $\mathrm{E}_{3}\left(\mathrm{~S}_{\mathrm{C}}\right.$ in Figure 1) opened to $2000 \mu \mathrm{m}$. This results in a flat-topped precursor ion peak (measured energy width $\Delta E=57 \mathrm{eV}$ at $50 \%$ peak height) and a low theoretical and realizable energy-resolving power of $176(E / \Delta E)$. In this case, the theoretical resolving power is equal to the realizable resolving power because the instrumental slit widths limit the realizable resolving power.

$$
R_{\mathrm{E}}=\frac{E}{\Delta E}=\frac{A_{\gamma}}{A_{\mathrm{x}} S_{0}+S_{1}+\Delta}
$$

The third factor that limits the realizable energyresolving power is an experimental factor: the kinetic energy distribution of the precursor ion main beam [11]. This experimental variable is most critical for the study of ions formed by ESI. Electrospray ionization 
typically results in precursor ions that have a large kinetic energy distribution [30]. In the course of our work, we have measured distributions that can range from 5 to $30 \mathrm{eV}$ (energy width at $50 \%$ peak height) dependent on ion source tuning conditions. It is imperative that the kinetic energy distribution (or energy width) of the precursor ion beam be restricted to $\leq 10 \%$ of the distributions (or energy widths) of the product ions. Without a narrow main beam energy distribution, it is impossible to obtain high realizable energy-resolving power. In "triple-sector" experiments in which the precursor ion beam is double focused prior to energy analysis, the kinetic energy distribution of the precursor ions is measured by scarning the last ESA across the ion beam [11], as done here. In double focusing, two-sector (BE or EB) instruments, the kinctic energy distribution of the precursor ions must be measured by using either accelerating voltage or $B^{2} / E$ scans, not ESA scans [11].

The preceding instrumental and experimental parameters are necessary to obtain accurate and reproducible product-ion peak shapes. To subsequently obtain accurate KERDs from the peaks, the mathematical algorithms need to include methods (1) to deconvolute the precursor ion kinetic energy distribution, (2) to smooth the deconvoluted peak, and (3) to calculate the KERD in a manner that accounts for instrumental $y$ and $z$-axial discrimination.

There is a simple method to perform a least-squares subtraction of the precursor ion kinetic energy width in the calculation of the KER at half-height $\left(T_{0.5}\right)$ for product ions that are Gaussian in shape (eq 2) [17]. This method is questionable, however, for the nonGaussian product-ion peak shapes observed here. Furthermore, the method is not applicable for use with a distribution function. Mathematical methods for deconvoluting the precursor ion kinetic energy distribution are needed instead. We tested a FT deconvolution routine $[17 \mathrm{~b}]$, but prefer to use the "pseudodeconvolution" method of Jones et al. [13], which was developed originally for optical data. The pseudo-deconvolution method is less sensitive to noise in the raw data than is the FT routine.

Smoothing of the deconvoluted data is necessary because the KERD calculation is sensitive to noise in the data. Standard smoothing routines (FT [31], boxcar, and Savitzky and Golay [14]) artificially broaden the peaks, which results in artificially large KERDs. Consequently, a method was developed to smooth the data so that peak broadening is minimized. The method is conceptually similar to that of Trott and Beynon [32] except we use repetitive 21-point Savitzky-Golay smooths.

Calculations of the KERDs were performed by using the method of Yeh and Kim [15]. We tested the TRAMP program developed by Rumpf and Derrick [25c], but the program gives incorrect KERDs for the SX102: It does not account for effects of the quadrupole lenses on the ion trajectories in the $y$-axial direction
[26]. The Yeh and Kim method takes all $y$ - and $z$-axial discrimination into account. It does not, however, account for smearing of the image that is caused by dissociations along the entire field-free region [33]. The effect of image smearing is negligible, however, for experiments that are performed at a high realizable energy-resolving power.

Results from our computational approach for acquisition of the KERDs are shown in Figures 3 and 4. The smoothing routine causes some peak distortion ["dips" in high and low energy sides of the deconvoluted/ smoothed peaks (smooth, solid lines) in Figure 3]. These distortions appear in the KERDs (Figure 4) as dips below zero probability. The center of the peak for the $\mathrm{b}_{6}^{+}$ion is also somewhat distorted by the smoothing routine, which causes a dip below zero probability at low KERs in Figure 4.

The most probable KER ( $T_{\text {m.p. }}$ ), which is the maximum of the KERD, would be equal to the average KER ( $T_{\text {ave. }}$ ) if the KERD were symmetrical around $T_{\text {m.p: }}$ In practice, this ideal situation rarely occurs [15b, 25b, c]. Consequently, $T_{\text {m.p. }}$ gives the most reproducible values and estimates of the average KER, in contrast to the actually calculated $T_{\text {ave }}$ : Peak asymmetry causes $T_{\text {ave }}$ to shift, but $T_{\text {m.p. }}$ remains the same. This is demonstrated in Table 3 in which the $T_{\text {m.p. }}$ for the $b_{6}^{+}$and $\mathrm{y}_{2}^{\prime \prime}{ }^{-1}$ ions remains the same, but $T_{\text {ave. }}$ changes. Thus, the $T_{\text {ave. }}$ values in Table 3 overestimate by $36 \mathrm{meV}$ the true average KER, which is best evaluated as being $T_{\text {m.p. }}(0.902 \pm 0.000 \mathrm{eV})$.

Others [28b, 34] have proposed that simple measurement of the energy widths of product ions from charge-separation reactions at $50 \%$ peak height and use of eq 1 to calculate $T_{0.5}$ can be used to obtain an acceptable estimate of the average KER. This assumption also is addressed in Table 3 , in which eq 1 is used to calculate $T_{0.5}$. The $T_{0.5}$ values overestimate $T_{\text {m.p. }}$ by $81 \mathrm{meV}$ and overestimate $T_{\text {ave. }}$ by $45 \mathrm{meV}$. Consequently, the data in Table 3 show that this assumption is not valid, which also is discussed more in subsequent text.

\section{Intercharge Distances: Ion Structures and Reaction Mechanisms}

The KER in a metastable ion decomposition measures the amount of the excess internal energy (vibrational and rotational) of the products that is converted into

Table 3. Summary of data from KER calculations

\begin{tabular}{clll}
\hline Ion & $T_{\text {m.p. }}{ }^{\text {b }}(\mathrm{eV})$ & $T_{\text {ave. }}{ }^{\mathrm{a}}(\mathrm{eV})$ & $T_{0.5}{ }^{\mathrm{b}}(\mathrm{eV})$ \\
\hline \hline $\mathbf{b}_{6}^{+}$ & 0.902 & 0.949 & 0.956 \\
$\mathrm{y}_{2}^{\prime+}$ & 0.902 & 0.928 & 1.01 \\
Ave. $( \pm \text { std. dev. })^{c}$ & $0.902(0.000)$ & $0.938(0.015)$ & $0.983(0.038)$
\end{tabular}

${ }^{a}$ Calculated from the KERDs shown in Figure 4.

${ }^{b}$ Calculated from the widths (50\% peak height) of the deconvoluted and smoothed product ion peaks shown in Figure 3 using eq 1.

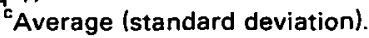


translational energy. In the case of a charge-separation reaction, a significant amount of the excess energy results from the translational energy of the products that arises from Coulomb repulsion. If all the KER arose from Coulomb repulsion, the KER would be equal to the work ( $\Delta T$ in electronvolts) required to bring the charges from infinity to a finite distance apart (eq 4 [35], in which $q=1.6022 \times 10^{19} \mathrm{C}, k=$ $8.98755 \times 10^{9} \mathrm{~N} \mathrm{~m}^{2} \mathrm{C}^{-2}, \varepsilon_{\mathrm{r}}$ is the relative permittivity (dielectric constant) of the medium (unitless), and $r$ is the intercharge distance (angstroms). (The constant 14.40 includes the conversion from SI units to electronvolts and angstroms.)

$$
\mathrm{KER}=\Delta T=\left[k\left|q q^{\prime}\right|\right] / \varepsilon_{\mathrm{r}} r=14.40 / \varepsilon_{\mathrm{r}} r
$$

Equation 4, with $\varepsilon_{\mathrm{r}}=1.00$ (vacuum), has been used previously to provide useful information about the most probable structures of doubly charged ions that decompose via charge-separation reactions [35a, 36-39]. Equation 4 also has been used to address the most probable structures of triply charged ions [16]. In the early studies, the precursor ions were small [35a, 36] and heteroatomic-substituted [37] hydrocarbons that were limited to $24-60$ vibrational degrees of freedom. More recently, eq 4 has been used to address structures of doubly charged ions that contain metal ions $[12,38]$ and the bimolecular reaction chemistry of $\mathrm{C}_{60}^{2+}, \mathrm{C}_{60}^{3+}$, and $\mathrm{C}_{70}^{2+}$ cations; the latter have $174\left(\mathrm{C}_{60}\right)$ and $204\left(C_{70}\right)$ degrees of freedom [39].

The reaction coordinate shown in Figure 6 details the thermochemical requirements for eq 4 to be correct in both the present and the foregoing $[12,16,35 \mathrm{a}$, 36-39] experiments. For $\Delta T$ to be equal to the KER, both must be equal to $\left(E_{0}-\Delta H_{r x n}\right)$. (For a bimolecular reaction, $E_{0}$ is the energy difference between the bimolecular reactants and the charge-separation transition state, and $\Delta H_{r x n}$ is the energy difference between the bimolecular reactants and products [39c].) The transition state is the point on the potential surface at which the covalent bond energy (short-range attractive

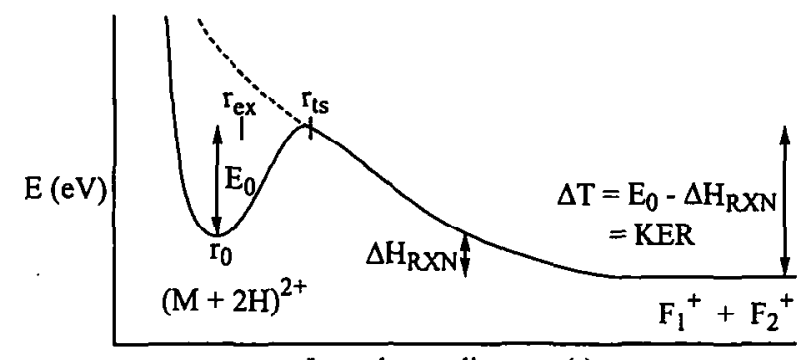

Intercharge distance $(r)$

Figure 6. Schematic potential energy surface for a charge-separation reaction that does not involve diabatic curve crossing [41]: $r_{0}$ is the equilibrium distance between the charges in the ground-state ion; $r_{e x}$ is the equilibrium distance between the charges in the vibrationally excited ion; $r_{t s}$ is the equilibrium distance between the charges in the transition state of the reaction coordinate; $E_{0}$ is the threshold energy of the reaction.
Table 4. Summary of intercharge distances calculated from KER data by using eq 4 and $\varepsilon_{\mathrm{r}}=1.00$

\begin{tabular}{ccc}
\hline KER value $\left( \pm\right.$ std. dev. $^{\mathrm{a}}(\mathrm{eV})$ & $r(\stackrel{\circ}{)})$ \\
\hline \hline$T_{\text {m.p. }}$ & $0.902(0.000)$ & $16.0(0.0)$ \\
$T_{\text {ave. }}$ & $0.938(0.015)$ & $15.4(0.2)$ \\
$T_{0.5}$ & $0.983(0.038)$ & $14.7(0.6)$ \\
\hline
\end{tabular}

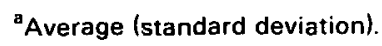

force) is exactly equal and opposite to the Coulomb energy (long-range repulsive force). Thus, from Figure 6, $\Delta T$ must be equal to the work required to bring the two charges from infinity to the distance $r_{\mathrm{ts}}$, which is the equilibrium distance between the two charges in the transition state. Consequently, for eq 4 to hold, the KER from any reverse chemical barrier, any conversion of bending vibrations into free rotations [40], and any excess energy above the transition state that is statistically partitioned into translation must be small compared to the Coulomb repulsion. It is important to realize that the reaction coordinate in Figure 6 involves a ground-state electronic surface of a closed-shell diprotonated ion: Diabatic curve crossing is not involved [41]. This is probably not the case for other studies [16, 35a, 36-39] that involve open-shell cations and dications formed by ionization of two electrons.

Using eq $4, \varepsilon_{r}=1.00$, and the other assumptions inherent in Figure 6, the data from the KERs measured here can be used to obtain values for the intercharge distance in the transition state of the decomposing $[\mathrm{M}+2 \mathrm{H}]^{2+}$ ions of angiotensin II (Table 4). The $T_{\text {m.p. }}$ gives an intercharge distance of $16.0 \pm 0.0 \AA$. In comparison, the calculated $T_{\text {ave. }}$ and $T_{0.5}$ values give underestimates of the intercharge distance (Table 4). These underestimations range from 0.6 to $1.3 \AA$, respectively. The $1.3-\AA$ underestimation of the intercharge distance derived from the $T_{0.5}$ values reiterates that measurements of $T_{0.5}[28,34]$ generally may be unreliable for experiments such as these in which there are multiple possible locations of the charge sites.

The experimentally measured intercharge distance of $16.0 \AA$ can be compared to the values obtained from the theoretical dynamics calculations (Tables 1 and 2), which are summarized in Structures 2 and $\mathbf{3}$. To obtain a singly charged $\mathrm{y}_{2}^{\prime \prime}$ ion, at least one ionizing proton must be on one of the two C-terminal amino acids. Thus, in the calculations, one proton was placed on either the C-terminal carboxylic acid carbonyl oxygen or on the amide carbonyl oxygen of the amide bond between Pro and Phe: These two locations are the most basic sites on the $\mathrm{C}$-terminus. Intercharge distances in the transition state are approximated by the intercharge distances obtained from structures at $1000 \mathrm{~K}$, which approximate the intercharge distances in the vibrationally excited ions ( $r_{\mathrm{ex}}$ in Figure 6). This approximation thus also assumes that $\left(r_{\mathrm{ts}}-r_{\mathrm{ex}}\right)$ in Figure 6 is minimal compared to the overall distance between the charges in the vibrationally excited ions. 


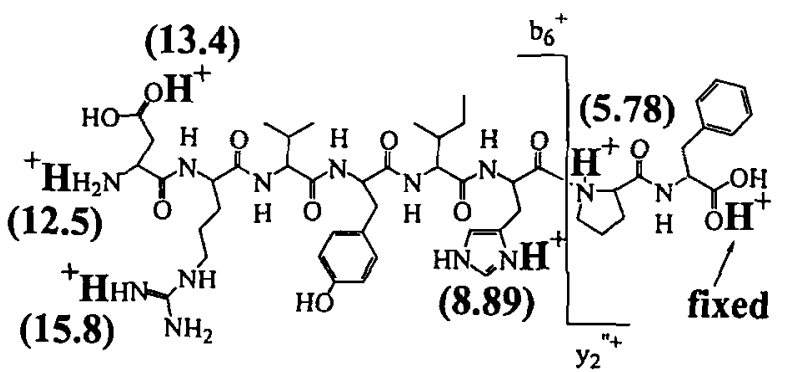

Structure 2

Structures that contain one proton on the Arg side chain and the other on the C-terminal carboxylic acid carbonyl oxygen give an intercharge distance of $15.8 \pm$ $3.1 \AA$ A (Structure 2, Table 1), which is virtually identical to the experimental measurement. Structures that contain one proton on the Arg side chain and the other on the C-terminal amide carbonyl oxygen give an intercharge distance of $15.4 \pm 3.4 \AA$ (Structure 3, Table 2), which is also close to the experimentally measured value.

The experimental and theoretical structural data can be used to address the mechanisms for formation of the $b_{6}^{+} / y_{2}^{\prime \prime}{ }^{+}$complementary ion pair. The most widely argued mechanism for formation of $\mathrm{b}_{n}^{+}$ions from protonated polypeptides involves a charge-induced heterolytic cleavage in which a proton is on the amide nitrogen of the amide bond being cleaved $[4 c, 6,7 c, d]$. For the doubly protonated precursor of angiotensin II, this mechanism by necessity would involve Scheme I. It is unreasonable to propose such a structure and corresponding mechanism, however, considering that the charges are only $5.78 \AA$ apart. If this precursor structure were formed, it is unlikely that it would give rise to the $y_{2}^{\prime \prime}{ }^{+}$ions. In analogy to reactions of doubly charged toluene [36b], hydrocarbon [35a, 36a], and amine [37] ions, a charge-separation reaction instead would be expected to cleave one of the bonds in the two C-terminal amino acids. Such a reaction would give a $T_{\text {m.p. }}$ of approximately $2.5 \mathrm{eV}$.

Consequently, the data instead support a rearrangement reaction, such as shown in Schemes II [10b, c] and III $[10 \mathrm{a}, \mathrm{b}]$, which are classic reactions of singly protonated peptides that give $y_{m-n}^{\prime \prime}$ product ions. These reactions are nominally charge-remote [42] as drawn in

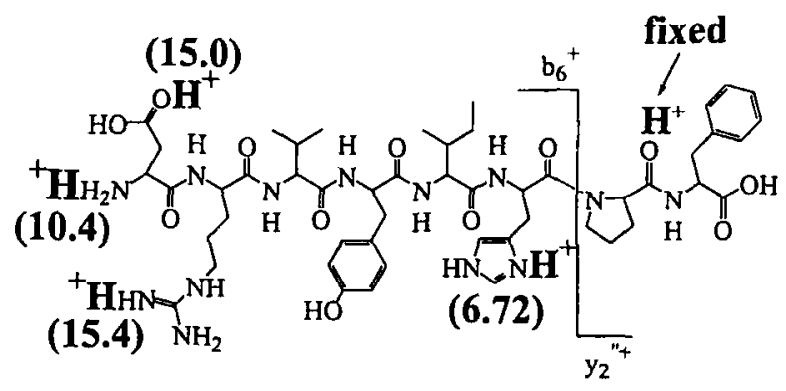

Structure 3

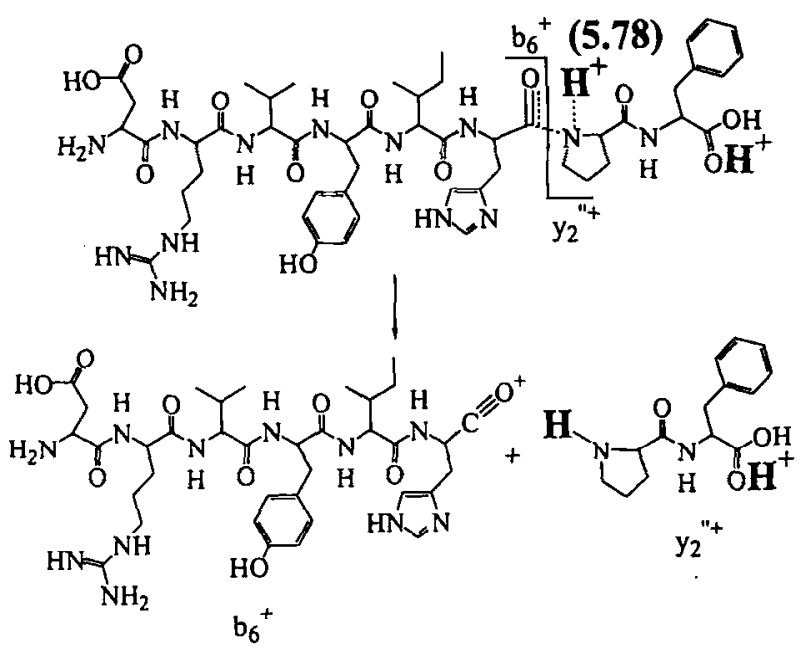

Scheme I

Schemes II and III . It should be noted, however, that the experimental and theoretical data do not rule out the possibility that the proton on the C-terminus is lucated on the carbonyl oxygen of the Pro-Phe amide bond, which would be close enough to the bond being cleaved to reduce the transition state energy so that the reaction would in essence be charge induced. It is also important to note that the location of charge in the product ions depicted in Schemes I-III represents the location of charge in the transition state structures. After cleavage and charge separation, the individual product ions may undergo unimolecular rearrangements to produce more stable structures.

These data not only address the reaction mechanisms, but show that the locations of protons in multiply charged ions may not be on the most basic residues. For angiotensin II, it would be expected that one proton would be on the Arg side chain and the other on His. This is not the case for the precursor structures that give rise to the $b_{6}^{+} / y_{2}^{\prime \prime}$ complementary pair. This finding supports the hypotheses of others [7b, c, 28] that in cases in which two basic sites are in relatively close proximity, the two protons may be located at

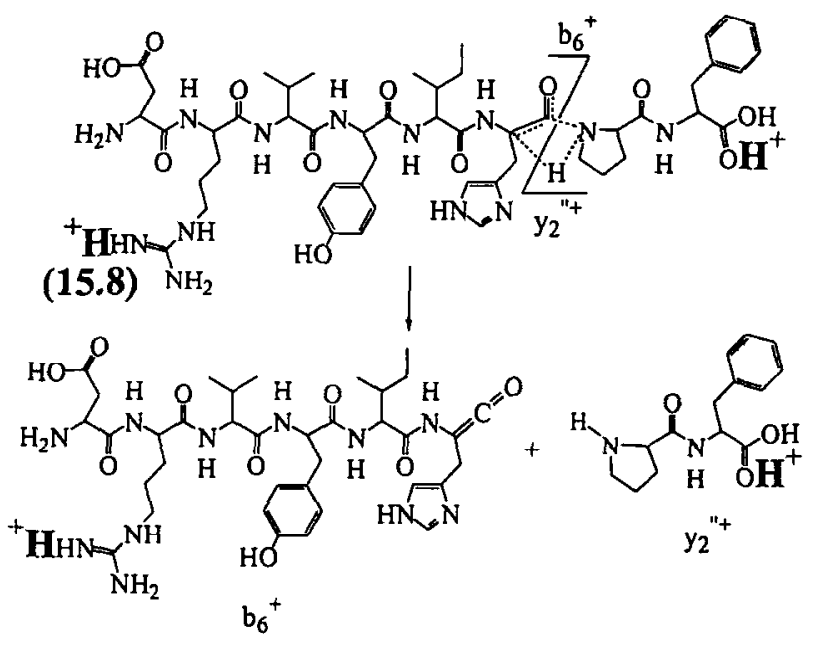

Scheme II 


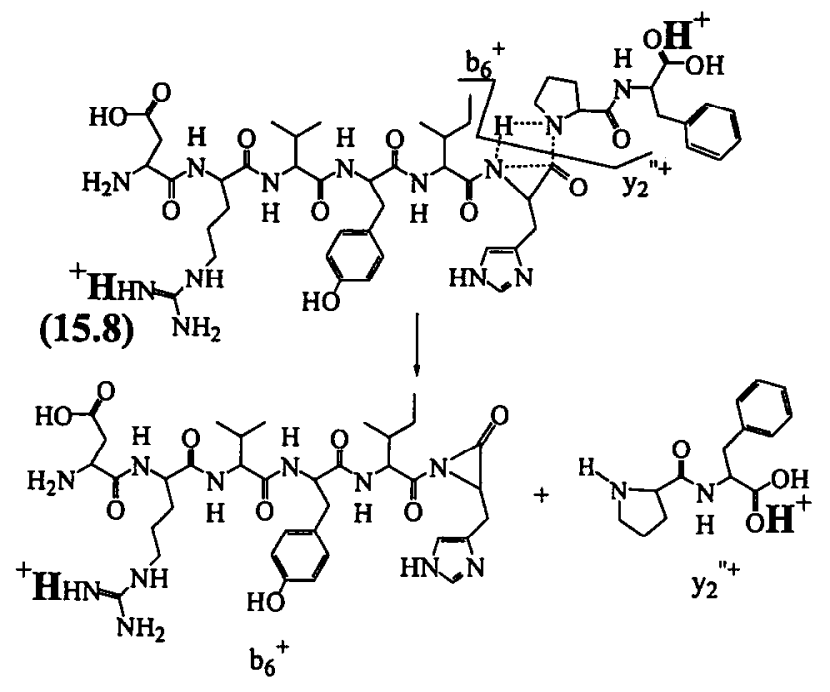

Scheme III

other sites that minimize Coulomb repulsion. This may not be the case for all the precursor isomers, however. We have preliminary evidence from $\mathrm{MS}^{3}$ experiments [43] that one of the two protons in the precursor isomers that decompose to give the doubly charged $\mathrm{b}_{6}^{\prime 2+}$ ions is bound to His: These data will be presented in a later article.

\section{Conclusions}

Data presented here conclusively show that chargeseparation reactions occur for large multiply charged ions formed by ESI. Instrumental discrimination causes low-mass complementary ions to be either undetected or weakly abundant in tandem mass spectra acquired by using scans at a constant $B / E$ [12]. Instrumental discrimination also may be the reason why low-mass complementary ions are either undetected or weakly abundant in tandem mass spectra acquired by using triple quadrupoles $[4 a, b]$. Instrumental discrimination also occurs in MIKES experiments, but the magnitude of the discrimination is dependent on ion optical design. For the SX102, $z$-axial discrimination occurs, but is reduced by the stigmatic focusing properties of the quadrupole lenses [26]. The mass dependency of instrumental discrimination against products of chargeseparation reactions means that the kinetic method may give unreliable results in studies of multiply charged proton-bound dimers if the effects of discrimination are ignored [28]. This will be the case for any instrument-be it sector, quadrupole, or FT-if the experimental conditions discriminate against ions that have large velocity distributions.

Evidence also is presented that the most probable KER $\left(T_{\text {m.p. }}\right)$ in charge-separation reactions, calculated from the KERD, may be used to address intercharge distance. Measurements of $T_{0.5}$, however, give poor approximations of the average KER. The close agreement between the experimental measurement of $T_{\text {m.p. }}$. and the theoretical structural calculations suggests that several assumptions inherent in the method are valid. These assumptions primarily rely on the predominance of the long range Coulomb repulsive force in the KER. Consequently, any conversion of internal energy into translation and any excess energy in the transition state that is partitioned into translation are relatively insignificant. Furthermore, the data suggest that an "effective molecular dielectric constant" of 1.00 is appropriate for decomposing ions such as these [43].

The data also conclusively show that protons in multiply charged ions may not be located on the most basic residues. This indicates that Coulomb repulsion may play a more important role in determination of precursor ion structure than perhaps previously envisioned.

The method demonstrated here has the potential to be applied in investigations of other important structural features of biomolecular ions-both anions and cations. For example, currently we are making use of KERDs in structural studies of singly and multiply charged coordination complexes between transition metal ions and peptides [12] to help determine metalion binding sites. We also are extending this method to larger and more highly charged systems. These latter experiments potentially can be used to provide constraints for molecular dynamics calculations of gasphase peptide or protein conformations. Relationships between gas-phase and solution conformations, the latter which are determined by two-dimensional NMR, can provide information with regard to the practical use of ESI-tandem mass spectrometry to study physiologically relevant structures. These include peptides or proteins whose three-dimensional structures are altered by metal-ion, substrate, or other binding interactions.

\section{Acknowledgments}

We acknowledge the National Science Foundation (CHE-9113272) and the Petroleum Research Fund (25280-AC), which is administered by the American Chemical Society, for funding, and the National Institutes of Health (1S10RR06276) and the National Science Foundation (CHE-9119862) for the use of the JEOL JMSSX102/SX102A/E as a shared instrument. Preliminary reports of this work were presented at the FACSS Conference, St. Louis, MO, October, 1994, the Sanibel Conference on Mass Spectrometry, Sanibel Island, FL, January, 1995, the Gordon Research Conference on Structures, Energetics, and Dynamics of Gaseous Ions, Ventura, CA, February, 1995, and the 43rd ASMS Conference on Mass Spectrometry and Allied Topics, Atlanta, GA, May, 1995.

\section{References}

1. Nohmi, T.; Fenn, J. B. J. Am. Chem. Soc. 1992, 114, 3241-3246.

2. (a) Winger, B. E.; Light-Wahl, K. J.; Rockwood, A. L.; Smith, R. D. J. Am. Chem. Soc. 1992, 114, 5897-5898; (b) Sackau, D.; Shi, Y.; Beu, S. C.; Senko, M. W.; Quinn, J. P.; Wampler, F. M.; McLafterty, F. W. Proc. Natl. Acad. Sci. USA 1993, 90, 790-793; (c) Loo, R. R. O.; Smith, R. D. J. Am. Soc. Mass Spectrom. 1994, 5, 207-220; (d) Wood, T. D.; Chorush, R. A.; Wampler, F. M.; Little, D. P.; O'Connor, P. B.; McLafferty, F. W. Proc. Natl. Acad. Sci. USA 1995, 92, 2451-2454. 
3. (a) Smith, R. D.; Loo, J. A.; Edmonds, C. G.; Barinaga, C. J.; Udseth, H. R. Anal. Chem. 1990, 62, 882-899; (b) Loo, J. A.; Edmonds, C. G.; Smith, R. D. Anal. Chem. 1991, 63, 2488-2499; (c) Senko, M. W.; Beu, S. C.; McLafferty, F. W. Anal. Chem. 1994, 66, 415-417; (d) Kolli, V. S. K.; Orlando, R. I. Am. Soc. Mass Spectrom. 1995, 6, 234-241.

4. (a) Barinaga, C. J.; Edmonds, C. G.; Udseth, H. R.; Smith, R. D. Rapid Commun. Mass Spectrom. 1989, 3, 160-164; (b) Smith, R. D.; Barinaga, C. J.; Udseth, H. R. J. Phys. Chem. 1989, 93, 5019-5022; (c) Tang, X.-J.; Boyd, R. K. Rapid Commun. Mass Spectrom. 1992, 6, 651-657; (d) Tang, X.-J.; Thibault, P.; Boyd, R. K. Anal. Chem. 1993, 65, 2824-2834.

5. Roepstorff, P.; Fohlman, J. Biomed. Mass Spectrom. 1984, 11 , 601.

6. (a) Kiryushkin, A. A.; Fales, H. M.; Axenrod, T.; Gilbert, E. J.; Milne, G. W. A. Org. Mass Spectrom. 1971, 5, 19-31; (b) Biemann, K.; Martin, S. A. Mass Spectrom. Rev. 1987, 6, 1-76; (c) Johnson, R. S.; Martin, S. A.; Biemann, K. Int. J. Mass Spectrom. lon. Processes 1988, 86, 137-154.

7. (a) Rockwood, A. L.; Busman, M.; Smith, R. D. Int. /. Mass Spectrom. Ion Processes 1991, 111, 103-129; (b) Fabris, D.; Kelly, M.; Murphy, C.; Wu, Z.; Fenselau, C. J. Am. Soc. Mass Spectrom. 1993, 4, 652-661; (c) Downard, K. M.; Biemann, K. J. Am. Soc. Mass Spectrom. 1994, 5, 966-975; (d) Ishikawa, K.; Nishimura, T.; Koga, Y.; Niwa, Y. Rapid Commun. Mass Spectrom. 1994, 8, 933-938.

8. (a) Loo, J. A.; Edmonds, C. G.; Udseth, H. R.; Smith, R. D. Anal. Chem. 1990, 62, 693-698; (b) Chowdhury, S. K.; Katta, V.; Chait, B. T. J. Am. Chem. Soc. 1990, 112, 9012-9013; (c) Guevremont, R.; Siu, K. W. M.; LeBlanc, J. C. Y.; Berman, S. S. J. Am. Soc. Mass Spectrom. 1992, 3, 216-224.

9. (a) Loo, J. A.; Loo, R. R. O.; Light, K. J.; Edmonds, C. G.; Smith, R. D. Anal. Chem. 1992, 64, 81-88; (b) LeBlanc, J. C. Y.; Guevremont, R.; Siu, K. W. M. Int. J. Mass Spectrom. Ion Processes 1993, 125, 145-153.

10. (a) Mueller, D. R.; Eckersley, M.; Richter, W. J. Org. Mass Spectrom. 1988, 23, 217-221; (b) Kenny, P. T. M.; Nomoto, K.; Orlando, R. Rapid Commun. Mass Spectrom. 1992, 6, 95-97; (c) Zhao, H.; Adams, J. Int. J. Mass Spectrom. Ion Processes 1993, 125, 195-205.

11. Strobel, F. H.; Adams, J. J. Am. Soc. Mass Spectrom. 1995, in press.

12. Sullards, M. C.; Adams, J. J. Am. Soc. Mass Spectrom. 1995, 6, 608-610.

13. Jones, R. N.; Venkataraghavan, R.; Hopkins, J. W. Spectrochim. Acta 1967, 23A, 925-939.

14. Savitzky, A.; Golay, M. J. E. Anal. Chem. 1964, 36, 1627-1639.

15. (a) Yeh, C.; Kim, M. S. Rapid Commun. Mass Spectrom. 1992, 6, 115-120; (b) Yeh, C.; Kim, M. S. Rapid Commun. Mass Spectrom. 1992, 6, 293-297.

16. Beynon, J. H.; Caprioli, R. M.; Baitinger, W. E.; Amy, J. W. Org. Mass Spectrom. 1970, 3, 661-668.

17. (a) Baldwin, M. A.; Derrick, P. J.; Morgan, R. P. Org. Mass Spectrom. 1976, 11, 440-442; (b) Mendez Amaya, A.; Mead, W. L.; Brenton, A. G.; Proctor, C. J.; Beynon, J. H. Int. J. Mass Spectrom. Ion Processes 1980, 36, 57-68.

18. (a) Dewar, M. J. S.; Zoebisch, E. G.; Healy, E. F.; Stewart, J. J. P. J. Am. Chem. Soc. 1985, 107, 3902-3909; (b) Dewar, M. J. S.; Dieter, K. M. J. Am. Chem. Soc. 1986, 108, 8075-8086; (c) Stewart, J. J. P. I. Computer-Aided Molec. Design 1990, 4, 1-105.

19. Berthod, H.; Giessner-Prettre, C.; Pullman, A. Theor. Chim. Acta 1967, 8, 212-222.

20. Weiner, S. J.; Kollman, P. A.; Nguyen, D. T.; Case, D. A. J. Comput. Chem. 1986, 7, 230-252.
21. (a) Thorne, G. C.; Ballard, K. D.; Gaskell, S. J. J. Am. Soc. Mass Spectrom. 1990, 1, 249-257; (b) Teesch, L. M.; Orlando, R. C.; Adams, J. J. Am. Chem. Soc. 1991, 113, 3668-3675; (c) Tang, X.; Ens, W.; Standing, K. G.; Westmore, J. B. Anal. Chem. 1988, 60, 1791-1799.

22. Klots, C. D. J. Chem. Phys. 1972, 58, 5364-5367.

23. Benson, S. W.; O'Neal, H. E. Kinetic Data of Gas Phase Unimolecular Reactions, NSRDS-NBS 21, 1970.

24. von Helden, G.; Wyttenbach, T.; Bowers, M. T. Science 1995, $267,1483-1485$.

25. (a) Szulejko, J. K.; Mendez Amaya, A.; Morgan, R. P.; Brenton, A. G.; Beynon, J. H. Proc. Roy. Soc. London Ser. A 1980, 373, 1-11; (b) Mendez Amaya, A.; Brenton, A. G.; Szulejko, J. E.; Beynon, J. H. Proc. Roy. Soc. London Ser. A 1980, 373, 13-25; (c) Rumpf, B. A.; Derrick, P. J. Int. J. Mass Spectrom. Ion Processes 1988, 82, 239-257.

26. Matsuda, H. Int. J. Mass Spectrom. Ion Processes 1985, 66, 209-215.

27. Orlando, R.; Boyd, R. K. Org. Mass Spectrom. 1992, 27, 151-155.

28. (a) Kaltashov, I. A.; Fabris, D.; Fenselau, C. C. J. Phys. Chem. 1995, 99, 10046-10051; (b) Kaltashov, I. A.; Fenselau, C. C. J. Am. Chem. Soc., 1995, 117, 9906-9910.

29. Holmes, J. L.; Terlouw, J. K. Org. Mass Spectrom. 1980, 15. $383,396$.

30. (a) Campbell, V. L.; Guan, Z.; Laude, D. A. J. Am. Soc. Mass Spectrom. 1994, 5. 221-229; (b) Hendrickson; C. L.; Drader, J. J.; Laude, D. A. I. Am. Soc. Mass Spectrom. 1995, 6, 76-79.

31. Horlick, G. Anal. Chem. 1972, 44, 943-947.

32. Trott, G. W.; Beynon, J. H. Int. J. Mass Spectrom. Ion Processes $1979,31,37-49$

33. Leather, C.; Wilkins, A. C. R.; Brenton, A. G. J. Am. Soc. Mass Spectrom. 1995, 6, 212-219.

34. Vkey, K.; Pcsfalvi, G. Org. Mass Spectrom. 1992, 27, 1203-1209.

35. (a) Beynon, J. H.; Fontaine, A. E. J. Chem. Soc. Chem. Commun. 1966, 717-719; (b) Atkins, P. W. Physical Chemistry, 3rd ed.; W. H. Freeman: New York, 1986.

36. (a) Ast, T.; Beynon, J. H.; Cooks, R. G. Org. Mass Spectrom. 1972, 6, 749-763; (b) Ast, T.; Beynon, J. H.; Cooks, R. G. Org. Mass Spectrom. 1972, 6, 741-747.

37. (a) Caprioli, R. M.; Beynon, J. H.; Ast, T. Org. Mass Spectrom. 1971, 5, 417-425; (b) Beynon, J. H.; Caprioli, R. M.; Ast, T. Org. Mass Spectrom. 1972, 16, 273-282; (c) Ast, T.; Beynon, J. H. Org. Mass Spectrom. 1973, 7, 503-513.

38. (a) Tonkyn, R.; Weisshaar, J. C. J. Am. Chem. Soc. 1986, 108, 7128-7130; (b) Drewello, T.; Lebrilla, C. B.; Schwarz, H.; Ast, T. J. Organomet. Chem. 1988, 339, 333-338; (c) Roth, L. M.; Freiser, B. S. Mass Spectrom. Rev. 1991, 10, 303-328.

39. (a) Petrie, S.; Javahery, G.; Wang, J.; Bohme, D. K. J. Phys. Chem. 1992, 96, 6121-6123; (b) Petrie, S.; Javahery, G.; Bohme, D. K. Int. J. Mass Spectrom. Ion Processes 1993, 124, 145-156; (c) Javahery, G.; Petrie, S.; Wincel, H.; Wang, J.; Bohme, D. K. J. Am. Chem. Soc. 1993, 115, 6295-6301.

40. Worry, G.; Marcus, R. A. J. Chem. Phys. 1977, 67, 1636-1646.

41. (a) Gill, P. M. W.; Radom, L. Chem. Phys. Lett. 1988, 147, 213-218; (b) Gill, P. M. W.; Radom, L. J. Am. Chem. Soc. 1989, 111, 4613-4622.

42. Adams, J. Mass Spectrom. Rev. 1990, 9, 141-186.

43. (a) Gross, D. S.; Williams, E. R. J. Am. Chem. Soc. 1995, 117, 883-890; (b) Gross, D. S.; Rodriguez-Cruz, S. E.; Bock, S.; Williams, E. R. J. Phys. Chem. 1995, 99, 4034-4038; (c) Schnier, P. D.; Gross, D. S.; Williams, E. R. J. Am. Chem. Soc. 1995, $117,6747-6757$. 